\title{
Teste de condutividade elétrica em sementes de linho
}

\author{
Electrical conductivity test on flex seeds
}

\section{Josiane Cantuária Figueiredo ${ }^{1} \odot$, Andréia Márcia Santos de Souza David ${ }^{1} \odot$, Cleisson Dener da $^{\circ}$ Silva1 ${ }^{\circledR}$, Larissa Medeiros Soares ${ }^{\circledR}{ }^{\circledR}$, Kennia Karoline Gonçalves Pereira ${ }^{1 \oplus}$, Rebeca Alves Nunes da Sílva ${ }^{1 \oplus}$ e Rayane Aguiar Alves ${ }^{1}{ }^{\oplus}$}

${ }^{1}$ Universidade Federal de Pelotas. Pelotas, RS, Brasil.

*Autor para correspondência: igor@iftm.edu.br

Conflitos de Interesse:

Os autores declaram não ter conflito de interesse

Licença:

Artigo publicado em acceso aberto sob uma licença Creative Commons CC-BY

Contribuição do autor:

Todos os autores fizeram contribuições substanciais para a concepção e desenho substanciais para a concepção e desenho deste estudo, para a análise e interpretação dos dados, revisão do manuscrito aprovação da versão final. Todos os autores assumem responsabilidade pelo conteúdo do manuscrito.

Histórico:

Recebido: 24/07/2020

Aceito: $08 / 11 / 202$

Período de publicaçao:

Julho-dezembro de 2021

\begin{abstract}
RESUMO
Para determinar a qualidade fisiológica de lotes de sementes o teste de condutividade elétrica tem se mostrado eficiente devido sua rapidez e facilidade na execução. Objetivou-se com o presente trabalho avaliar o teste de condutividade elétrica, considerando, lotes, número de sementes e volumes de água, buscando estabelecer a metodologia mais adequada para a estratificação de lotes. O trabalho foi conduzido no Laboratório de Análise de Sementes do Departamento de Ciências Agrárias da Universidade Estadual de Montes Claros (DCA/UNIMONTES), Janaúba, MG, utilizando-se quatro lotes de sementes de linhaça da safra 2017. Inicialmente, determinou-se, o teor de água, germinação, primeira contagem de germinação, emergência de plântulas, índice de velocidade de emergência, comprimento, massa fresca e seca de plântulas. O teste de condutividade elétrica foi realizado com 25 e 50 sementes embebidas em 25, 50 e $75 \mathrm{~mL}$ de água deionizada nas temperaturas de 25 e $30^{\circ} \mathrm{C}$, com leituras 24 horas de embebição. O teste de condutividade elétrica conduzido com quatro repetições de 25 sementes puras embebidas em $75 \mathrm{~mL}$ de água deionizada, na temperatura de $30^{\circ} \mathrm{C}$, permitiu a separação dos lotes, mostrando-se promissor na avaliação da qualidade das sementes de linhaça.

Palavras-chave: germinação, linhaça, lotes, qualidade fisiológica.
\end{abstract}

\section{ABSTRACT}

In order to determine the physiological quality of seed lots the electrical conductivity test has shown to be efficient due to its speed and ease of execution. The objective of this study was to evaluate the electrical conductivity test, considering water volumes, number of seeds and conditioning temperatures, in order to establish the methodology more suitable for batch stratification. Four batches of flax seed of the golden group were used. Initially, water content, germination, first germination count, seedling emergence and emergence speed index were determined. The electrical conductivity test was performed with the following variations: 25 and 50 seeds soaked in 25, 50 and $75 \mathrm{~mL}$ of distilled water at temperatures of 25 and $30^{\circ} \mathrm{C}$, with readings 24 hours of imbibition. The most suitable condition for the electrical conductivity test of flax seeds is the soaking of 25 seeds in $75 \mathrm{~mL}$ of water at $30^{\circ} \mathrm{C}$.

Key words: germination, "Flax", lots, physiological quality.

\section{INTRODUÇÃO}

A linhaça (Linum usitatissimum L.) é o alimento de origem vegetal rico em ácidos graxos $\omega$-3, apresentando também quantidades elevadas de fibras, proteínas e compostos fenólicos. O grão pode ser consumido in natura, inteiro ou moído, também pode ser utilizado como ingrediente na preparação de produtos de panificação, sobremesas e produtos cárneos.

No Brasil o principal destino da linhaça é na indústria, na qual utilizam como componente de secante de tintas, vernizes, corantes, linóleos e biodiesel (Oliveira et al., 2012).

Para o estabelecimento adequado de uma lavoura de linhaça é imprescindível o emprego de sementes de alta qualidade, gerando plântulas fortes, vigorosas, bem desenvolvidas e que se desenvolva nas diferentes condições edafoclimáticas, com maior velocidade de emergência e de desenvolvimento das plantas.

Para análise mais precisa da qualidade das sementes, faz-se necessário complementar as informações fornecidas pelo teste de germinação com testes de vigor, possibilitando assim, selecionar os melhores lotes para comercialização e semeadura (Araújo et al., 2011).

O teste de condutividade elétrica das sementes, dentre os demais testes rotineiramente utilizados, oferece vantagens, como o fato de detectar o primeiro sintoma de deterioração de sementes, isto é, a perda da integridade estrutural das membranas celulares da semente (Kryzanowski, Vieira y França Neto, 1999). 
A condutividade elétrica visa avaliar indiretamente a intensidade dos danos causados às membranas celulares resultantes do processo de deterioração da semente (Abreu et al., 2011)

Baseia-se no princípio de que, com o processo de deterioração, ocorre aumento da lixiviação dos constituintes celulares das sementes embebidas em água, devido à perda da integridade dos sistemas de membranas celulares (Gonzales, Paula y Valerí, 2009).

Diversos são os fatores que podem afetar os resultados nos testes de condutividade elétrica, pelo que se enfatizam os atributos e quantidades de água usada na imersão das sementes, tempo de imersão, teor de água, peso, volume, número, integridade e idade das sementes, genótipo e temperatura (Rodrigues, Villela, Tillmann e Carvalho, 2006).

Assim, torna-se necessário o desenvolvimento e padronização de uma metodologia adequada que possibilite a reprodutibilidade do procedimento e a obtenção de resultados precisos de condutividade elétrica, garantindo assim, uma maior confiabilidade na determinação do vigor das sementes.

Devido à escassez de informações referentes à metodologia do teste de condutividade elétrica para sementes de linhaça, objetivou-se neste trabalho avaliar sua eficiếncia considerando diferentes lotes, número de sementes, volumes de água e temperaturas de embebição, buscando estabelecer a metodologia mais adequada para a estratificação de lotes.

\section{MATERIAL E MÉTODOS}

O trabalho foi conduzido no Laboratório de Análise de Sementes do Departamento de Ciências Agrárias da Universidade Estadual de Montes Claros (DCA/ UNIMONTES), Janaúba, MG, utilizando-se quatro lotes de sementes de linhaça da safra 2017.

\section{Experimento I (caracterização dos lotes)}

Para a caracterização dos lotes foram realizadas determinações e testes descritos a seguir:

Teor de água: realizado pelo método da estufa a $105 \pm 3^{\circ} \mathrm{C}$, utilizando-se quatro repetições de 50 sementes para cada lote, sendo os resultados expressos em porcentagem (Ministério da Agricultura, Pecuária e Abastecimento, 2009).

Germinação - foi realizada seguindo os critérios estabelecidos pelas Regras para Análise de Sementes (Ministério da Agricultura, Pecuária e Abastecimento, 2009), semeando 50 sementes sobre duas folhas de papel germitest, umedecidas com água deionizada em volume equivalente a 2,5 vezes o seu peso seco e dispostas em caixas plásticas tipo gerbox. Após esse procedimento, as caixas contendo as sementes foram mantidas em germinador digital previamente regulado à temperatura de constante de $20^{\circ} \mathrm{C}$. As avaliações foram realizadas no terceiro e sétimo dia após a semeadura, e os resultados expressos em porcentagem. Consideram-se como normais as plântulas que apresentavam todas as estruturas essenciais que permitissem uma avaliação correta das mesmas. Essas plântulas mostram capacidade para continuar seu desenvolvimento e dar origem a plantas normais.

Primeira contagem de germinação: realizada simultaneamente com o teste de germinação, considerando-se a porcentagem de plântulas normais obtidas no terceiro dia após a semeadura (Ministério da Agricultura, Pecuária e Abastecimento, 2009).

Emergência de plântulas: conduzido sob condições ambientais de laboratório, utilizando areia anteriormente lavada e esterilizada em estufa a $200{ }^{\circ} \mathrm{C}$, durante duas horas. As sementes foram semeadas a $0,3 \mathrm{~cm}$ de profundidade em caixas tipo gerbox e o teor de água mantido com irrigações leves diariamente (Ministério da Agricultura, Pecuária e Abastecimento, 2009). Foram utilizadas quatro repetições de 50 sementes por lote e os resultados obtidos pelo número de plântulas emergidas, determinado por ocasião do sétimo dia após a montagem do experimento.

Índice de velocidade de emergência: conduzido em conjunto com o teste de emergência de plântulas, em condições ambientais controladas de laboratório, anotando-se diariamente, no mesmo horário, o número de plântulas germinadas normais até a estabilização da emergência. Ao final do teste, com os dados diários do número de plântulas emergidas, foi calculado o índice de velocidade de emergência, empregando-se a fórmula proposta por Maguire (1962).

Comprimento de plântulas: foram utilizadas quatro repetições de 10 plântulas normais escolhidas ao acaso, provenientes da última contagem do teste de emergência.

Massa fresca de plântulas: Foi realizado através de quatro repetições de 10 plântulas inteiras com parte aérea e raízes. Após a medição realizou-se a pesagem em uma balança analítica de precisão digital.

Massa seca de plântulas: Foi realizado através de quatro repetições de 10 plântulas inteiras com parte aérea e raízes. Após a coleta as plântulas foram colocadas em estufa a $65 \pm 3{ }^{\circ} \mathrm{C}$, durante 72 horas, aonde atingiram peso constante.

Experimento II (lotes $x$ número de sementes $x$ volumes de água $x$ temperatura)

As combinações estudadas foram as seguintes: lotes, número de sementes, volumes de água para embebição e temperaturas, utilizando-se quatro repetições de 25 e 50 sementes, com os volumes de 25, 50 e $75 \mathrm{~mL}$ de água deionizada colocados em copos descartáveis com capacidade para 200 $\mathrm{mL}$, para os 4 lotes estudados. As sementes de linhaça foram pesadas, em seguida adicionou-se a água deionizada e na sequência foram postas em cấmaras $\mathrm{BOD}$ à 25 e $30^{\circ} \mathrm{C}$ pelo período de 24 horas. As medidas da condutividade elétrica (CE) foram determinadas com um condutivímetro Conductivity Meter, modelo CD-4303 e os resultados expressos em $\mu S \mathrm{~cm}^{-1} \mathrm{~g}^{-1}$ de sementes.

O delineamento experimental empregado nos dois experimentos foi o inteiramente casualizado, com quatro repetições. O experimento II caracterizou-se como um fatorial $4 \times 2 \times 3 \times 2$, sendo os fatores 
representados pelos lotes, números de sementes, volumes de água de embebição e temperaturas.

As médias obtidas das avaliações de cada lote foram comparadas pelo teste de Tukey a $5 \%$ de probabilidade de erro, sendo que para essas análises utilizou-se o programa estatístico SISVAR.

\section{RESULTADOS E DISCUSSÃO}

Os dados referentes ao teor de água foram semelhantes entre as sementes dos quatro lotes estudados (Tabela 1), sendo a amplitude de variação entre 6,1 e $7,0 \%$, demonstrando que não houve interferência do mesmo nos resultados obtidos nos testes de vigor, uma vez que essas variações estão situadas dentro do limite, que é de até $2 \%$ (Marcos Filho, 2015). Esse fator é importante para a confiabilidade das demais avaliações e o fornecimento de resultados consistentes. Não permitindo que as análises realizadas sejam afetadas por diferenças na atividade metabólica, velocidade de umedecimento e na intensidade de deterioração das sementes por diferenças iniciais do teor de água (Coimbra, Martins, Tomaz e Nakagaw, 2009).

Pelos resultados do teste de germinação (Tabela 1) não foi possível separar os lotes em níveis distintos de viabilidade. A semelhança na germinação entre os lotes de sementes é de fundamental importância em estudos com objetivo de ajuste de metodologia para avaliação do vigor das sementes, pois o objetivo de um teste de vigor é detectar diferenças significativas na qualidade fisiológica de lotes de sementes com germinação semelhante, porém com diferença quanto ao vigor (Marcos-Filho e Novembre 2009).

Vale ressaltar que todos os lotes de sementes avaliados atenderam ao percentual mínimo aceitável de germinação para produção e comercialização de sementes de linhaça que é de $70 \%$ (Ministério da Agricultura, Pecuária e Abastecimento, 2011).

Conforme os dados da Tabela 1, nota-se diferença significativa na primeira contagem da germinação dos lotes avaliados, sendo que os lotes 1, 2 e 4 apresentaram-se mais vigorosos em relação ao lote 3 .

A primeira contagem de germinação é considerada um teste de vigor simples, realizado simultaneamente com o teste de germinação e parte do pressuposto de que as sementes mais vigorosas germinam primeiro (Abud, Araujo, Araujo, Araujo \& Pinto, 2013).

Os resultados do teste de emergência, comprimento, massa fresca e seca de plântulas foram semelhantes entre todos os lotes de sementes avaliados, conforme a germinação das sementes (Tabela 1). De acordo com Marcos-Filho (2015), o teste de emergência de plântulas é menos sensível para encontrar diferenças de vigor, quando comparado aos testes baseados na integridade das membranas e aos que avaliam a tolerância ao estresse.

De maneira semelhante ao teste de primeira contagem de germinação, o índice de velocidade de emergência permitiu classificar os lotes em níveis distintos de viabilidade, sendo que os lotes 1, 2 e 4 apresentaramse mais vigorosos em relação ao lote 3 .

Através dos dados de condutividade elétrica obtidos na interação número de sementes x volumes de água (Tabela 2) pode-se observar que a combinação de 25 sementes de linhaça embebidas em $50 \mathrm{~mL}$ de água na temperatura de $25^{\circ} \mathrm{C}$, foi a que melhor representou os resultados obtidos na caracterização dos lotes (Tabela 1). Os lotes 1, 2 e 4 foram considerados de melhor qualidade devido a menor liberação de lixiviados, quando comparado com o lote 3 .

Esteresultadoécompatível comasinformaçõesobtidas nos testes de vigor realizados para caracterização do potencial fisiológico dos lotes avaliados (Tabela 1). Durante o condicionamento das sementes para realização do teste, inicialmente ocorre uma intensa lixiviação dos constituintes celulares no meio líquido, tanto pelas sementes intactas e vigorosas, como pelas danificadas, tornando-se difícil a identificação de possíveis diferenças de qualidade entre os lotes, logo no início da imersão (Muraro, Luan, Kulczynski, Basso e Pedroso, 2017).

Tabela 1. Resultados médios, em porcentagem, do teor de água (TA), germinação (GER), primeira contagem de germinação (PC), emergência de plântulas (EP), índice de velocidade de emergência (IVE) comprimento de plântulas (CP), massa fresca (MF) e massa seca (MS) de plântulas de linhaça.

Variáveis

\begin{tabular}{|c|c|c|c|c|c|c|c|}
\hline \multirow{2}{*}{$\begin{array}{l}\text { Lotes } \\
\qquad 1\end{array}$} & \multirow{2}{*}{$\begin{array}{l}\text { TA (\%) } \\
\text { PC(\%) } \\
6,1 a^{*}\end{array}$} & \multicolumn{2}{|c|}{$\mathrm{GE}(\%)$} & \multirow{2}{*}{$\begin{array}{r}\text { EP(\%) } \\
82 a\end{array}$} & \multirow{2}{*}{$\begin{array}{c}\text { IVE } \\
14,20 a\end{array}$} & \multirow{2}{*}{$\begin{array}{l}\mathrm{CP}(\mathrm{cm}) \\
\mathrm{MF}(\mathrm{g}) \\
5,2 \mathrm{a} \\
1,41 \mathrm{a}\end{array}$} & \multirow{2}{*}{$\begin{array}{l}\mathrm{MS}(\mathrm{g}) \\
0,15 \mathrm{a}\end{array}$} \\
\hline & & $76 a$ & $38 \mathrm{a}$ & & & & \\
\hline 2 & $6,7 \mathrm{a}$ & 80 a & $38 a$ & $85 \mathrm{a}$ & $14,50 \mathrm{a}$ & $\begin{array}{l}5,5 \mathrm{a} \\
1,36 \mathrm{a}\end{array}$ & 0,17 a \\
\hline 3 & $6,3 a$ & 78 a & $28 b$ & $81 \mathrm{a}$ & 7,15 b & $\begin{array}{l}5,7 \mathrm{a} \\
1,38 \mathrm{a}\end{array}$ & $0,15 \mathrm{a}$ \\
\hline 4 & $7,0 \mathrm{a}$ & 78 a & $36 a$ & $80 a$ & $12,10 \mathrm{a}$ & $\begin{array}{l}5,8 \mathrm{a} \\
1,40 \mathrm{a}\end{array}$ & $0,14 a$ \\
\hline CV(\%) & 9,1 & 2,3 & 13,2 & 10,2 & 11,8 & 9,8 & 5,3 \\
\hline
\end{tabular}

*Médias seguidas pela mesma letra na coluna não diferem entre si pelo teste de Tukey a $5 \%$ de significância. 
Tabela 2. Condutividade elétrica ( $\mu \mathrm{S} \mathrm{cm}^{-19-1)}$ em função do número de sementes, volume de água para quatro lotes de sementes utilizando a temperatura de $25^{\circ} \mathrm{C}$.

\begin{tabular}{|c|c|c|c|}
\hline \multirow{2}{*}{ Lote } & \multicolumn{3}{|c|}{ Volume de água $(\mathrm{mL})$} \\
\hline & 25 & 50 & 75 \\
\hline & \multicolumn{3}{|c|}{25 sementes } \\
\hline 1 & $587,31 a^{*}$ & $391,04 b$ & $260,06 a$ \\
\hline 2 & 599,10 a & $370,18 b$ & $255,40 a$ \\
\hline 3 & 603,89 a & 441,43 a & 247,05 a \\
\hline 4 & 498,90 a & $378,92 b$ & $214,12 a$ \\
\hline \multirow[t]{2}{*}{$C V(\%)$} & \multicolumn{3}{|c|}{14,83} \\
\hline & \multicolumn{3}{|c|}{50 sementes } \\
\hline 1 & $562,71 \mathrm{a}$ & $310,87 a$ & 218,18 a \\
\hline 2 & $514,78 a$ & $315,81 \mathrm{a}$ & $230,06 a$ \\
\hline 3 & 547,57 a & 320,03 a & $212,90 \mathrm{a}$ \\
\hline 4 & 529,42 a & $337,37 \mathrm{a}$ & 198,47 a \\
\hline $\mathrm{CV}(\%)$ & \multicolumn{3}{|c|}{6,91} \\
\hline
\end{tabular}

*Médias seguidas de letras distintas na coluna, diferem entre si pelo teste de Tukey a 5\% de probabilidade.

Tabela 3. Condutividade elétrica ( $\mu \mathrm{S} \mathrm{cm}^{-19-1)}$ em função do número de sementes, volume de água para quatro lotes de sementes utilizando a temperatura de $30^{\circ} \mathrm{C}$.

\begin{tabular}{|c|c|c|c|}
\hline \multirow{2}{*}{ Lote } & \multicolumn{3}{|c|}{ Volume de água (mL) } \\
\hline & 25 & 50 & 75 \\
\hline & \multicolumn{3}{|c|}{25 sementes } \\
\hline 1 & $765,54 a *$ & 324,78 bc & $279,91 b$ \\
\hline 2 & 643,72 a & $338,06 a b$ & $233,06 \mathrm{c}$ \\
\hline 3 & $724,21 \mathrm{a}$ & 350,09 a & 318,76 a \\
\hline 4 & $612,28 \mathrm{a}$ & $311,50 \mathrm{c}$ & $241,43 c$ \\
\hline \multirow[t]{2}{*}{$\mathrm{CV}(\%)$} & \multicolumn{3}{|c|}{6,72} \\
\hline & \multicolumn{3}{|c|}{50 sementes } \\
\hline 1 & $601,65 \mathrm{a}$ & $285,68 b$ & $225,62 a$ \\
\hline 2 & 611,29 a & $285,20 b$ & 206,22 a \\
\hline 3 & 603,45 a & 316,20 a & $220,68 a$ \\
\hline 4 & 653,16 a & $275,91 b$ & $219,50 a$ \\
\hline $\mathrm{CV}(\%)$ & \multicolumn{3}{|c|}{8,05} \\
\hline
\end{tabular}

*Médias seguidas de letras distintas na coluna, diferem entre si pelo teste de Tukey a $5 \%$ de probabilidade.

No entanto, com o decorrer deste processo, a quantidade de lixiviados liberados pelas sementes vigorosas tende a estabilizar, em razão, principalmente, da reorganização das membranas, favorecendo a estratificação dos lotes de acordo com sua qualidade (Menezes, Garcia, Bahry e Mattioni, 2007).
No teste de condutividade elétrica (CE) o vigor das sementes está relacionado à integridade do sistema de membranas celulares. Desta forma, quando as sementes são hidratadas em água, há liberação dos lixiviados, em intensidade proporcional ao estado de desorganização dessas membranas. Sendo assim, os menores valores de CE indicam qualidade superior das sementes. 
Quando se utilizou 50 sementes, independentemente da quantidade de água $(25,50$ e $75 \mathrm{~mL})$ na temperatura de $25^{\circ} \mathrm{C}$, não foi eficiente na separação dos lotes em diferentes níveis de qualidade (Tabela 2); no entanto, Dutra, Medeiros Filho e Diniz (2007), com sementes de Senna siamea (Lam.); Oliveira e Novembre (2005), com sementes de pimentão e Vidigal, Lima, Bhering e Dias (2008), com sementes de pimenta, conseguiram eficiência para a ordenação de lotes quanto à qualidade fisiológica.

Observando a Tabela 3, nota-se que o teste de condutividade elétrica quando realizado na temperatura de $30^{\circ} \mathrm{C}$ com 25 sementes imersas em $75 \mathrm{~mL}$ de água, foi possível a separação dos lotes em 3 classes distintas de vigor, sendo que os lotes 2 e 4 obteve as menores quantidades de solutos lixiviados, no comparativo com os demais lotes.

Assim, o aumento da temperatura de embebição associados ao volume de água e quantidade de sementes interferiu na eficiência do teste em classificar os lotes em diferentes níveis de viabilidade.

Combinações de 50 sementes, imersas em $50 \mathrm{~mL}$ de água deionizada na temperatura de $30{ }^{\circ} \mathrm{C}$ (Tabela 3), por sua vez, proporcionou classificação de lotes semelhante à obtida no procedimento 25 sementes com $50 \mathrm{~mL} / 25^{\circ} \mathrm{C}$ (Tabela 2).

O teste de condutividade elétrica apresenta informações desejáveis para uso de rotina em laboratório de análise de sementes, devido sua facilidade na execução, separação consistente dos lotes, objetividade, rapidez e um controle de qualidade mais dinâmico e efetivo.

Os testes de vigor aplicados às sementes, principalmente o teste de condutividade elétrica, quando comparados com os testes de germinação proporcionam informações mais detalhadas sobre níveis de qualidade dos diferentes lotes de sementes.

\section{CONCLUSÕES}

O teste de condutividade elétrica conduzido com quatro repetições de 25 sementes puras embebidas em $75 \mathrm{~mL}$ de água deionizada, na temperatura de $30{ }^{\circ} \mathrm{C}$, permitiu a separação dos lotes, mostrando-se promissor na avaliação da qualidade das sementes de linhaça.

\section{AGRADECIMENTOS}

Ao Conselho Nacional de Desenvolvimento Científico e Tecnológico (CNPq), à Coordenação de Aperfeiçoamento de Pessoal de Nível Superior (CAPES) e à Fundação de Amparo à Pesquisa do Estado de Minas Gerais (FAPEMIG) pela concessão de bolsas e apoio financeiro.

\section{REFERÊNCIAS BIBLIOGRÁFICAS}

Abreu, L. A de. S., Carvalho, M. L. M de., Pinto, C. A. G., Kataoka, V. Y. (2011). Teste de condutividade elétrica na avaliação de sementes de girassol armazenadas sob diferentes temperaturas. Revista Brasileira de Sementes, 33 (4), 635642.
Abud, H. F., Araujo, E. F., Araujo, R. F., Araujo, A. V. \& 'Pinto, C. M. F. (2013). Qualidade fisiológica de sementes das pimentas malagueta e biquinho durante a ontogênese. Pesquisa Agropecuária Brasileira, 12 (88), 1546-1554.

Araújo, R. F., Zonta, J. B., Araújo, E. F., Heberle, E. \& Zonta, F. M. G. (2011). Teste de condutividade elétrica para sementes de feijão-mungo-verde. Revista Brasileira de Sementes, 33 (1), 123130.

Ministério da Agricultura, Pecuária e Abastecimento. (2011). Portaria no 16, de 25 de janeiro de 2013, DOU de 28/01/2013, No 19, Seção 1, $2 \mathrm{p}$.

Ministério da Agricultura, Pecuária e Abastecimento. (2009). Regras para análise de sementes. Brasília: MAPA/ACS, 399 p.

Coimbra, R. A., Martins, C. C., Tomaz, C.A. \& Nakagawa, J. (2009). Testes de vigor utilizados na avaliação da qualidade fisiológica de lotes de sementes de milho-doce (sh2). Ciência Rural, 39 (9), 2402-2408.

Dutra, A. S., Medeiros Filho, S. \& Diniz, F. O. (2007).' Teste de condutividade elétrica em sementes de Senna siamea (Lam.) H.S. Irwin \& Barneby. Revista Ciência Agronômica, 38 (3), 280-285.

Gonzales, J. L. S., Paula, R. C. \& Valerí, S. V. (2009). Teste de condutividade elétrica em sementes de Albizia hassleri (Cho,dat) Burkart. Fabaceaemimosoideae. Revista Arvore, 33 (4), 625-634.

Kryzanowski, F. C.; Vieira, R. D. \& França Neto, J. B.(1999). Vigor de sementes: Conceitos e testes. Londrina: ABRATES, $218 \mathrm{p}$.

Maguire, L. D. (1962). Speed of germination-aid in selection and evolution for seedling emergence and vigor. Crop Science, 2 (2), 176-177.

Marcos Filho, J. (2015). Fisiologia de sementes de plantas cultivadas. Piracicaba: FEALQ, 495 p.

Marcos Filho, J. \& Novembre, A.D.L.C. (2009). Avaliação do potencial fisiológico de sementes de hortaliças. In W.M. Nascimento (Ed.). Tecnologia de sementes de hortaliças. Brasília, DF: Embrapa Hortaliças, 185-246.

Menezes, N. L., Garcia, D. C., Bahry, C.A. \& Mattioni, N. M. (2007). Teste de condutividade elétrica em aveia preta. Revista Brasileira de Sementes, 29 (2), 138-1427.

Muraro, D. S., Luan, C., Kulczynski, S. M., Basso, C. J. \& Pedroso, D. S. (2017). Teste de condutividade elétrica em sementes de painço (Panicum miliaceum L.). Revista Brasileira de ciências agrárias, 12 (4), 490-495.

Oliveira, M. R., Santos, R. F., Rosa, H. A., Werner, O., Vieira, M. D. \& Delai, J. M. (2012). Fertirrigação da cultura de linhaça Linum usitatissimum L. Revista Brasileira de Energias Renováveis, 1, 22-32.

Oliveira, S. R. S. \& Novembre, A. D. L. C. (2005). Teste de condutividade elétrica para as sementes de pimentão. Revista Brasileira de Sementes, 27 (1), 31-36.

Rodrigues, M. B. C., Villela, F. A., Tillmann, M. A. A. \& Carvalho, R. (2006). Pré-hidratação em sementes de soja e eficiência do teste de condutividade elétrica. Revista Brasileira de sementes, 28 (2), 168-181.

Vidigal, D. S., Lima, J. S., Bhering, M. C. \& Dias, D. C. F. S. (2008). Teste de condutividade elétrica em sementes de pimenta. Revista Brasileira de Sementes, 30 (1), 168-174. 